\title{
Obesity: systemic and pulmonary complications, biochemical abnormalities, and impairment of lung function
}

\author{
Thiago Thomaz Mafort ${ }^{1}$, Rogério Rufino ${ }^{1,2}$, Cláudia Henrique Costa ${ }^{1,2}$ and Agnaldo José Lopes ${ }^{1,2^{*}}$
}

\begin{abstract}
Obesity is currently one of the major epidemics of this millennium and affects individuals throughout the world. It causes multiple systemic complications, some of which result in severe impairment of organs and tissues. These complications involve mechanical changes caused by the accumulation of adipose tissue and the numerous cytokines produced by adipocytes. Obesity also significantly interferes with respiratory function by decreasing lung volume, particularly the expiratory reserve volume and functional residual capacity. Because of the ineffectiveness of the respiratory muscles, strength and resistance may be reduced. All these factors lead to inspiratory overload, which increases respiratory effort, oxygen consumption, and respiratory energy expenditure. It is noteworthy that patterns of body fat distribution significantly influence the function of the respiratory system, likely via the direct mechanical effect of fat accumulation in the chest and abdominal regions. Weight loss caused by various types of treatment, including low-calorie diet, intragastric balloon, and bariatric surgery, significantly improves lung function and metabolic syndrome and reduces body mass index. Despite advances in the knowledge of pulmonary and systemic complications associated with obesity, longitudinal randomized studies are needed to assess the impact of weight loss on metabolic syndrome and lung function.
\end{abstract}

Keywords: Obesity, Metabolic syndrome, Lung function

\section{Background}

In recent decades, the prevalence of obesity has increased dramatically, and it has become the most common metabolic disease worldwide, leading to a global epidemic [1]. The etiology of obesity is complex and multifactorial and results from the interaction of genes with the environment, lifestyle, and emotional factors. The modern lifestyle is a potent risk factor for obesity. Declining physical activity levels and increased caloric intake are important environmental factors contributing to obesity $[2,3]$.

The increasing number of overweight and obese individuals is a serious public health problem that has implications for society and healthcare systems on a global

\footnotetext{
* Correspondence: agnaldolopes.uerj@gmail.com

'Laboratory of Respiration Physiology, Pulmonary Medicine Department, Pedro Ernesto University Hospital, State University of Rio de Janeiro,

Boulevard 28 de Setembro, 77, Vila Isabel 20551-030, Rio de Janeiro, Brazil

${ }^{2}$ Postgraduate Programme in Medical Sciences, State University of Rio de

Janeiro, Av. Prof. Manoel de Abreu, 444, Vila Isabel 20550-170, Rio de Janeiro, Brazil
}

scale. The economic consequences of obesity and associated diseases are not limited to high medical costs but also include indirect or social costs such as decreased quality of life, problems in social adjustment, lost productivity, disability associated with early retirement, and

Several systemic complications are associated with obesity, some of which lead to severe impairment of organs and tissues. These complications involve mechanical changes caused by the accumulation of adipose tissue and the numerous cytokines produced by adipocytes [5]. The effects of obesity on the respiratory system have been increasingly studied. The accumulation of fat in the body causes changes in respiratory physiology, with consequent impairment of various lung function parameters. Different patterns of body fat distribution differentially and negatively affect the function of the respiratory system [6]. 


\section{Review}

\section{Systemic complications related to obesity}

Although the relationship between obesity and pulmonary dysfunction is becoming increasingly clear, there is still much controversy regarding whether it occurs in other populations. Complex diseases such as asthma, obstructive sleep apnea (OSA), and chronic obstructive pulmonary disease (COPD) are multifactorial diseases that involve interactions among environmental, genetic, and behavioral factors [7]. Obesity is associated with various diseases and is an important cardiovascular risk factor. Overweight status promotes metabolic and structural changes that increase susceptibility to various diseases, including cardiovascular diseases, metabolic disorders, renal and biliary diseases, and certain types of cancer [7].

Obese individuals exhibit a persistent proinflammatory state that leads to insulin resistance, endothelial dysfunction, systemic arterial hypertension (SAH), and dyslipidemia. These factors culminate in type 2 diabetes mellitus (T2DM) and promote atherogenesis, which in turn increases the risk of coronary heart disease, stroke, and heart failure $[8,9]$.

Several studies have shown a direct correlation between obesity and OSA. However, the exact pathophysiology of OSA in obese patients remains poorly understood [10]. The mechanisms involved include an increase in neck circumference as well as the direct action of adipose tissue on the airways via a decrease in the luminal diameter of the airway and an increase in the probability of airway collapse $[11,12]$.

Asthma is also correlated with obesity. Obese individuals with asthma are more likely to have difficult-to-control complications and diseases, and individuals with a higher body mass index (BMI) have a greater risk of developing asthma. The mechanisms involved in this association include increased bronchial hyperresponsiveness (BHR), functional respiratory decline with decreased respiratory volume and flow, chronic systemic inflammation triggered by increased levels of inflammatory cytokines and chemokines, and factors derived from adipocytes, including leptin, adiponectin, and plasminogen activator inhibitor [13, 14]. Several other factors also appear to contribute to the increased risk of asthma in obese individuals, including changes in respiratory function, low exercise tolerance, and predisposition to gastroesophageal reflux $[15,16]$.

A possible relationship between obesity and COPD has been discussed. An epidemiological study of 650,000 patients revealed that the prevalence of obesity was significantly higher in patients with COPD than in those without COPD (24.6 and $17.1 \%$, respectively, $p<0.0001$ ) [17]. Because pro-inflammatory mediators are present in both obese individuals and in individuals with COPD, these mediators may be the connection between these two conditions [18].
More than one-fifth of the population of the United States and approximately $60 \%$ of obese individuals have metabolic syndrome [19]. In this context, an association between metabolic syndrome and pulmonary disease has been widely debated in recent years [20, 21]. Metabolic syndrome has been identified as an independent risk factor for worsening respiratory symptoms, impairment of lung function, asthma, and pulmonary hypertension. Several possible mechanisms have been proposed to explain these associations, including exposure to high insulin levels during fetal maturation (which induces alterations in airway smooth muscle), the effects of abdominal adiposity, deregulation of adipokine metabolism, and inflammation induced by fat in the lungs [22].

In the gastrointestinal tract, obesity is associated with gastroesophageal reflux disease, cholelithiasis, and liver steatosis. In the osteoarticular system, obesity is correlated with an increased prevalence of osteoarthritis, and in the reproductive system, obesity is correlated with female infertility, polycystic ovary syndrome, and erectile dysfunction [23].

Obesity is also associated with cancers of the breast, cervix, colon, endometrium, esophagus, kidney, liver, ovaries, prostate, and rectum. Furthermore, obese women have a higher prevalence of depression, menorrhagia, amenorrhea, and urinary incontinence. During pregnancy, obesity is associated with a higher risk of maternal complications; obese patients also have a higher incidence of adverse fetal outcomes [23].

\section{Biochemical and molecular changes}

Obesity is associated with a state of chronic systemic inflammation that is driven predominantly by the action of substances released by adipose tissue. Chronic inflammation is caused by activation of the innate immune system, which promotes a pro-inflammatory state and oxidative stress (OS) and a consequent systemic acute-phase response [5]. Systemic inflammation may play a crucial role in the pathogenesis of various obesity-related complications, including metabolic syndrome, T2DM, cardiac disease, liver dysfunction, and cancer.

Adipose tissue is an endocrine and energy storage organ composed of adipocytes, fibroblasts, endothelial cells, and immune cells. These cells secrete hormones and cytokines (adipokines) that exert endocrine, paracrine, and autocrine functions. Under physiological and pathological conditions, adipokines induce the production of reactive oxygen species (ROS), which trigger OS; this, in turn, leads to increased production of other adipokines. During this process, immune cells produce free oxygen radicals that promote a systemic proinflammatory state [24].

Excess adipose tissue is associated with the production of various proinflammatory cytokines, including tumor necrosis factor- $\alpha$ (TNF- $\alpha)$, interleukin-1- $\beta$ (IL-1 $\beta)$, and 
interleukin-6 (IL-6) [25]. TNF- $\alpha$ plays a critical role in the inflammatory response of the immune system as well as in the apoptosis of adipose cells, lipid metabolism, hepatic lipogenesis, and the induction of OS. Increased levels of TNF- $\alpha$ promote a response via the release of IL-6, another proinflammatory molecule, and the reduction of levels of anti-inflammatory cytokines such as adiponectin. TNF- $\alpha$ also increases the interaction of electrons with oxygen, generating superoxide anions. TNF- $\alpha$ levels are elevated in obese individuals and decrease with weight loss [26].

IL-1 $\beta$ is a pyrogenic cytokine that is released primarily by monocytes in response to tissue damage or infection. It has recently been proposed that IL- $1 \beta$ is also associated with the proinflammatory response in obesity via the increased production of other cytokines, including IL-6 [27]. IL-6 is secreted by adipocytes, endothelial cells, pancreatic cells, macrophages, and monocytes and participates in the regulation of energy homeostasis and inflammation. IL-6 influences the transition from acute to chronic inflammation by stimulating the synthesis of pro-inflammatory cytokines and the down-regulation of anti-inflammatory targets [28]. Visceral adipose tissue secretes two or three times more IL- 6 than subcutaneous adipose tissue via the production of other proinflammatory molecules [29]. In humans, high levels of IL-6 are associated with glucose intolerance, T2DM, SAH, and especially obesity. This cytokine may also suppress the activity of lipoprotein lipase and modulate central appetite control at the hypothalamic level [30].

Obese individuals are also more susceptible to oxidative damage. The accumulation of adipose tissue, particularly visceral adipose tissue, induces the synthesis of proinflammatory cytokines, including TNF- $\alpha$, IL-1, and IL-6. These cytokines promote the generation of reactive oxygen and nitrogen species by macrophages and monocytes, which may lead to increased OS [25]. ROS induce the release of pro-inflammatory cytokines and the expression of adhesion molecules, including connective tissue growth factor, insulin-like growth factor I, platelet-derived growth factor, and vascular cell adhesion molecule I, all of which trigger OS and appear to accelerate aging and cell death, with numerous systemic consequences [29, 31].

Another mechanism involved in the increased susceptibility of obese individuals to oxidative damage is the depletion of enzymes that are active in antioxidant pathways, including superoxide dismutase (SOD), glutathione peroxidase, and catalase. Antioxidant pathways associated with vitamins $\mathrm{A}, \mathrm{C}$, and $\mathrm{E}$ and beta-carotene also seem to be depleted [32]. Compared with normal-weight individuals, SOD activity is significantly decreased in obese subjects [33]. Oxidative damage leads to the increased production of free radicals, OS, mitochondrial DNA damage, and depletion of adenosine triphosphate, culminating in damage to cellular structures. The cellular damage caused by this lipotoxic state is a direct consequence of the cascade of proinflammatory cytokines released by adipose tissues [34].

Adipose tissue is a source of several bioactive adipokines, including leptin, adiponectin, visfatin, resistin, apelin, and type I plasminogen activation inhibitor (PAI-I). These adipokines are directly associated with physiological and pathological processes involving OS [5].

Leptin is a hormone that is secreted by adipocytes in amounts that are directly proportional to adipose tissue mass and triglyceride levels. The function of leptin is primarily anorexigenic; it binds to proteins, circulates in the plasma, reaches the central nervous system, and promotes satiety. However, it has been postulated that obesity is associated with increased levels of leptin and that a decrease in leptin's anorexigenic effect via resistance mechanisms occurs in obese patients [25]. The mechanism by which leptin promotes OS has not been determined. However, one hypothesis is that hexamethylene bis-acetamide inducible-1 (Hexim1) is involved in maintaining whole-body energy balance [35]. These hormones may act by inducing the synthesis of cytokines such as TNF- $\alpha$, interleukin-2 (IL-2), and interferon- $\gamma$ and can exert their functions in various cell types, including $\mathrm{T}$ cells, monocytes, neutrophils, and endothelial cells [36]. Studies have also shown that leptin increases serum levels of C-reactive protein (CRP), confirming its pro-inflammatory effect [36].

In contrast to leptin, adiponectin, which is secreted by differentiated adipocytes, has anti-inflammatory and antiatherogenic effects. It inhibits the adhesion of monocytes to endothelial cells, the transformation of macrophages into foam cells, and the activation of endothelial cells [37]. Adiponectin also decreases TNF- $\alpha$ and CRP levels and increases the release of nitric oxide (NO) from endothelial cells. A deficiency in this hormone results in decreased levels of NO and reduced leukocyte adhesion, leading to chronic vascular inflammation [38]. It has also been observed that TNF- $\alpha$ and IL- 6 are potent inhibitors of the synthesis of adiponectin and other adipokines, including visfatin. Exposure of adipocytes to high levels of ROS also suppresses the production of adiponectin. These mechanisms explain why low levels of adiponectin are found in obese individuals [39].

Visfatin, a recently discovered adipokine, has been positively correlated with the accumulation of adipose tissue. In addition, the level of this hormone decreases with weight loss [40]. Visfatin has pro-oxidant and pro-inflammatory activity and is elevated in obese individuals compared with normal-weight individuals [41]. It stimulates leukocytes and the production of pro-inflammatory cytokines (IL-1, IL-6, and TNF- $\alpha$ ) and promotes the generation of ROS [41].

Resistin, a compound present at low levels in adipocytes and at high levels in circulating monocytes, was 
initially described as an adipokine that is involved in the regulation of appetite, energy balance, and insulin resistance. However, other studies have shown that resistin is associated with an increase in the incidence of cardiovascular disease in obese individuals. The mechanisms involved are directly related to OS and involve the activation of endothelial cells and the upregulation of adhesion molecules and pro-inflammatory cytokines in vascular walls [42].

In summary, the dysfunction of adipose tissue can induce systemic OS and lead to abnormal production of adipokines, which contributes to the development of obesity-related disorders. Furthermore, the level of oxidative damage biomarkers is increased in obese individuals and is directly correlated with BMI, percentage of body fat, and levels of triglycerides and low-density lipoproteins [43]. The accumulation of fat, particularly abdominal visceral fat, impairs antioxidant mechanisms [44]. All these events lead to a chronic and persistent proinflammatory state that results in systemic pathologies.

\section{Obesity and lung function}

Obesity affects the respiratory system by several mechanisms, including direct mechanical changes due to fat deposition on the chest wall, abdomen, and upper airway as well as systemic inflammation [45]. It increases the work of breathing and, therefore, increases neural respiratory drive, in addition to causing respiratory sleep disorders and eventually hypercapnic respiratory failure [46]. In this context, tests of pulmonary function may be useful in evaluating whether a physiological change can be explained by the well-known effects of obesity on the respiratory system. Moreover, the detection of changes in the respiratory system resulting from obesity may be important because several of these changes can be reversed by weight loss or by surgical treatment of obesity (Fig. 1).

In normal respiration, the diaphragm contracts, pushing the abdominal contents down and forward. At the same time, the contraction of the external intercostal muscles pulls the ribs upward and forward [47]. In obese individuals, this mechanism is impaired because the excess body fat that lines the chest and occupies the abdomen limits the action of the respiratory muscles. These structural changes in the thoracic-abdominal area restrict diaphragmatic mobility and rib movement, which promotes changes in the dynamics of the respiratory system and reduces its compliance, leading to mechanical impairment of the respiratory muscles [48]. Reduction in lung compliance can also result from increased pulmonary blood volume, closure of dependent airways with the formation of small areas of atelectasis, or increased alveolar surface tension due to a reduction in FRC $[45,49]$. In addition, changes in the neural control of breathing and increases in thoracic blood volume due to fat deposition

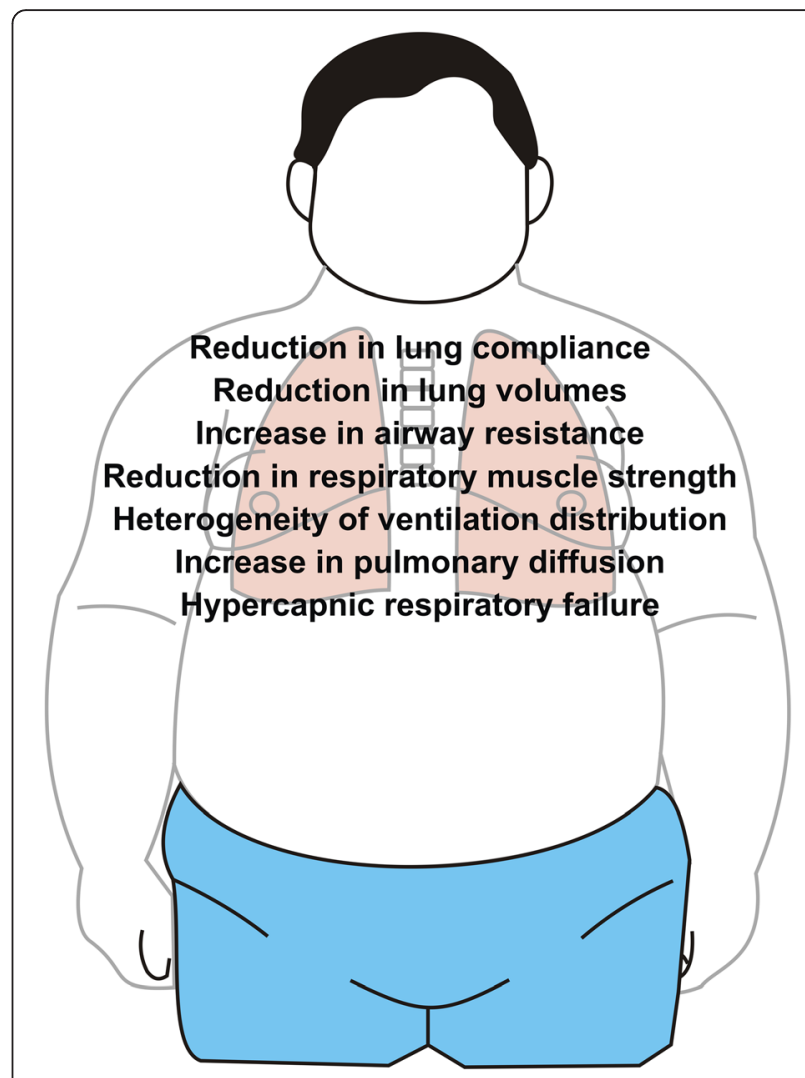

Fig. 1 Pulmonary function abnormalities resulting from obesity

in the chest also promote changes in pulmonary function parameters [50]. Of note, Rasslan et al. [51] observed that adipose tissue is an endocrine and paracrine organ that produces many cytokines and bioactive mediators, resulting in a pro-inflammatory state that may be associated with pulmonary hypoplasia, atopy, BHR, and increased risk of asthma in obese individuals.

\section{Lung volume}

Evaluation of static lung volume primarily indicates a reduction in the expiratory reserve volume (ERV), functional residual capacity (FRC), and total lung capacity (TLC). Reductions in FRC and ERV are detectable even at a modest increase in weight. This results from a shift in the balance of inflationary and deflationary pressures on the lung due to the mass load of adipose tissue around the rib cage and abdomen [49]. Elevated intra-abdominal pressure can be transmitted to the chest. This dramatically reduces the FRC and ERV and requires patients to breathe in a less efficient part of their pressure-volume curve, which in turn increases the work of breathing [46].

Jones and Nzekwu [52] reported that decreases in ERV, FRC, and TLC seem to exhibit an exponential correlation with increased BMI and are directly correlated with the mechanical effects produced by fat deposition in the chest and abdomen. According to this study, 
obesity decreases respiratory system compliance and creates mechanical restraints on the muscles responsible for breathing. In addition, Mafort et al. [53] used spirometry and whole body plethysmography to evaluate 30 patients who were overweight or obese and showed that the primary change in lung volume in these patients was reduced ERV. According to these authors, deposition of fat in the thoracic-abdominal region is one of the main causes of the observed reduction in ERV. It is noteworthy that marked reductions in ERV may lead to abnormalities in ventilation distribution, with closure of airways in the dependent zones of the lung and inequalities in the ventilation-perfusion ratio [49].

\section{Airway function}

Despite an association with increased BMI, airway function as measured by spirometry is little affected by obesity except in morbidly obese individuals [45]. However, the use of spirometry to evaluate lung function in morbidly obese subjects revealed a proportional reduction in forced vital capacity (FVC) and forced expiratory volume in one second $\left(\mathrm{FEV}_{1}\right)$, suggesting the occurrence of restrictive lung disease $[54,55]$. The reduction in $\mathrm{FEV}_{1}$ and FVC appears to be directly associated with the degree of obesity in morbidly obese subjects with more severe restrictions. However, obesity has little direct effect on airway caliber. The $\mathrm{FEV}_{1} /$ FVC ratio is generally well preserved or elevated even in morbidly obese individuals, indicating that $\mathrm{FEV}_{1}$ and FVC are affected at the same rate [56]. A reduction in expiratory flows in an obese individual is unlikely to indicate bronchial obstruction unless the flow measurements have been normalized for the reduction in FVC [49].

Whole-body plethysmography, impulse oscillometry, or the forced oscillation technique (FOT) can also be used to assess the mechanical properties of the airways in obese individuals, more precisely through the measurement of airway resistance (Raw) [57]. Given that Raw is highly dependent on lung volume and hence is affected by any reduction in the FRC, Raw is increased in obese individuals. In contrast, specific airway resistance, which is corrected for lung volume, is within the normal range in such individuals. However, some studies have suggested that the increase in Raw is not completely explained by reduced lung volume because differences between obese individuals and non-obese individuals may persist after correction of Raw for lung volume [57, 58]. The cause of the increase in Raw is unknown; one possibility is that the structure of the airway may be remodelled by exposure to proinflammatory adipokines or by lipid deposition [49].

\section{Respiratory muscle strength}

The function of the respiratory muscles may be impaired with increasing obesity, possibly due to the load imposed on the diaphragm. The observed dysfunction of the respiratory muscles can be partially explained by the increased resistance imposed by the presence of excess fatty tissue on the chest and abdomen, which causes mechanical disadvantage to these muscles [59].

Respiratory muscle strength can be assessed by measuring maximal inspiratory pressure (MIP) and maximal expiratory pressure (MEP). In obese individuals, both MIP and MEP may be reduced. The impairment of respiratory muscles is multifactorial; although some studies indicate that the diaphragm exhibits higher electromyographic activity in obese individuals than in normal-weight individuals, ineffective muscle contraction and premature fatigue also occur [50,60, 61], indicating that the reduction in MIP and MEP may be due to distension of the diaphragmatic muscles, increased respiratory effort, and ineffective muscle biomechanics caused by fat deposition in the thoracic and abdominal regions. Moreover, when in the supine position, the weight of the abdomen in obese individuals causes the diaphragm to ascend into the chest, resulting in the closure of small airways at the base of the lung and thereby generating an intrinsic positive end-expiratory pressure that results in increased ventilatory work and consequent muscle impairment $[60,61]$.

\section{Ventilation distribution and gas exchange}

Most obese individuals present an arterial partial pressure of oxygen $\left(\mathrm{PaO}_{2}\right)$ within the normal range. However, among morbidly obese subjects, the alveolar-arterial oxygen gradient $\left[\mathrm{P}(\mathrm{A}-\mathrm{a}) \mathrm{O}_{2}\right]$ is slightly widened because of the presence of areas of atelectasis and maldistribution of ventilation, which can cause a major ventilation-perfusion imbalance. In these individuals, the lower parts of the lungs are relatively poorly ventilated and perfused, possibly due to the closure of small airways, whereas the upper regions of the lungs exhibit enhanced ventilation $[45,62]$.

When assessing the carbon monoxide lung diffusion capacity (DLco), it should be noted that lung tissue perfusion is a determining factor because most perfused areas have higher concentrations of red blood cells and consequently higher diffusion of this gas than nonperfused areas. This factor is important when evaluating the diffusion of gases in obese individuals. Fat deposition in the thoracic region leads to higher vascularization in this area. This explains, at least in part, the increase in the DLco observed in the obese population [63]. In a recent study, the authors observed elevated DLco in $23.3 \%$ of obese individuals, and elevated DLco was most frequent in individuals with the highest accumulation of fat in the thoracic region $\left(r_{s}=0.42 ; p<0.01\right)$ [64].

\section{Relationships between obesity, asthma, and bronchial hyperresponsiveness}

Obesity has been associated with a higher incidence, prevalence, and severity of asthma and with altered 
pulmonary function, poor treatment response, and high morbidity [15, 65-68]. The incidence of asthma is 1.47 times higher in obese individuals than in non-obese individuals, and a three-unit increase in BMI is associated with a $35 \%$ increase in the risk of asthma $[69,70]$. Decreases in FRC and tidal volume in addition to sedentary lifestyle and limited ability to perform + physical activities among obese individuals may worsen asthma symptoms $[15,71,72]$. In a cohort study of more than 25,000 children and adults with asthma, Schatz et al. [73] showed that a higher BMI was associated with worsened asthma control and an increased risk of asthma exacerbations.

The inflammatory changes described in obese individuals have been cited as factors that might affect the clinical manifestations of asthma in these individuals. The inflammatory condition of an obese individual, which includes higher expression levels of leptin, adiponectin, TNF- $\alpha$, transforming growth factor- $\beta$ (TGF- $\beta$ ), CRP, and eotaxin, determines how these inflammatory mechanisms overlap with those involved in asthma and may exacerbate the influence of these cytokines on the contractility of the muscles of the airways $[68,74]$.

By reducing functional lung volume, obesity can change airway diameter due to the interdependence of the airway and the adjacent pulmonary parenchyma; these effects favor the development of BHR even in non-asthmatic individuals. BHR has the potential to enhance the effects of obesity on airway closure and hence on the distribution of ventilation [49]. Torchio et al. [68] evaluated 41 healthy subjects through the methacholine challenge test measured in a body plethysmograph and FOT and demonstrated that BHR was significantly associated with obesity. These authors also observed that in obese men, but not in obese women, BHR was associated with a decrease in lung volume. However, it remains unclear whether conditions associated with BHR, such as obesity, are a risk factor for asthma. Studies have provided conflicting results. Confounding factors include the different mechanisms involved in obesity and asthma, self-reported diagnosis of asthma, gender differences, the absence of synergistic effects of obesity and asthma on lung function, and the use of different methods to measure lung function [75-77].

Although the association between asthma and obesity remained uncertain until recently, the existence of different asthma phenotypes is now well recognized. More recently, Bates [78] highlighted two phenotypes of asthma in obese individuals: an early-onset allergic (EOA) form that is complicated by obesity and a late-onset non-allergic (LONA) form that occurs only in the setting of obesity. Whereas obese LONA asthmatics have more compliant airways, obese EOA asthmatics display considerable inflammatory thickening of the airways. Thus, these two phenotypes appear to be quite distinct pathological conditions in obese individuals with asthma.
Patterns of body fat distribution and pulmonary function Accumulation of fat in the thoracic and abdominal regions is likely to directly affect the downward movement of the diaphragm and chest wall properties [49]. The pattern of body fat distribution seems to be relevant to the changes in lung function observed in overweight and obese individuals. Changes in chest wall compliance are more affected by the amount of fat in both the chest and upper abdomen than by the amount of fat only in the chest, suggesting that respiratory system mechanics may differ in obese individuals with the same BMI but with different patterns of body fat distribution [45]. The pattern of body fat distribution can be assessed using several strategies, including anthropometric methods, electrical bioimpedance, and dual-energy X-ray absorptiometry (DXA) [79-81]. Bioelectrical impedance analysis (BIA) has been widely used due to its high speed of information processing and because it is a non-invasive, convenient, and relatively inexpensive method that estimates the distribution of fluids in the intra- and extracellular spaces in addition to the body components [82]. DXA is a noninvasive method and is considered the gold standard for body composition assessment. It uses low-dose x-rays and permits the assessment of both total body fat and fat in various body compartments, including the thoracic, android, and gynoid regions $[64,83]$.

Obesity is associated with reduced respiratory system compliance, which itself is exponentially correlated with BMI, waist circumference, and waist-hip ratio [45]. Nevertheless, lung volumes are only slightly associated with BMI, whereas DXA-derived variables present highly significant correlations with FRC and ERV in both men and women [49]. The android pattern of body fat deposition appears to negatively influence lung volume and lung capacity by generating increased resistance to diaphragmatic contraction and impairing respiratory mechanics. This would also explain the greater loss in $\mathrm{FEV}_{1}$ and FVC in obese men than in women with a corresponding BMI because the gynoid pattern prevails in women $[84,85]$. In a recent study, Mafort et al. found a significant correlation between TLC and waist circumference $\left(r_{s}=-0.34 ; p=0.03\right)$. These results reinforce the idea that abdominal fat plays a role in the development of restrictive lung disease and its deleterious effect on mechanical ventilation [64].

\section{Dyspnea on exertion in obese individuals}

Dyspnea on exertion is a common complaint of obese adults. However, the mechanism responsible for this symptom is not well defined yet [86]. Almost $40 \%$ of obese individuals complain of dyspnea on exertion, an incidence that is higher than that in general population [87]. Obesity has clear potential to directly affect respiration during exercise because there is an increase in oxygen consumption $\left(\mathrm{VO}_{2}\right)$ and carbon dioxide production 
$\left(\mathrm{VCO}_{2}\right)$ due to stiffening of the respiratory system with the increase in mechanical work needed to sustain exercise. Thus, even a slight increase in minute ventilation $\left(V_{E}\right)$ relative to resting levels can result in a considerable increase in the ratio between $\mathrm{VO}_{2}$ and respiratory work in obese adults. This ratio increases considerably in conditions in which higher levels of $V_{E}$ are required, as during exercise, and this may result in dyspnea on exertion [87-89].

Cardiopulmonary exercise testing (CPX) can provide valuable information on the performance of the cardiac and respiratory systems in obese individuals with dyspnea on exertion. Using CPX, Bernhardt et al. [87] compared obese men with dyspnea grade $\leq 2$ with those with dyspnea grade $\geq 4$ assessed by the Borg scale. In that study, the authors found no association between the level of perception of dyspnea and $\mathrm{VO}_{2}$ and concluded that differences in the intensity of exercise, ventilatory demand, cardiovascular fitness, or quality of the respiratory sensation do not seem to play an important role in the development of dyspnea on exertion in these individuals. Also using CPX, Hothi et al. [90] evaluated $\mathrm{VO}_{2 \max } / \mathrm{kg}$ in 152 obese individuals and 173 non-obese individuals with severe heart failure (HF). They found that $\mathrm{VO}_{2 \max } / \mathrm{kg}$ is not a reliable indicator of cardiac fitness in all patients. Instead, they found that despite having lower $\mathrm{VO}_{2 \max } / \mathrm{kg}$, obese patients with $\mathrm{HF}$ are capable of generating higher cardiac power than nonobese patients with HF. These results argue against the widespread use of $\mathrm{VO}_{2 \max } / \mathrm{kg}$ as a cardiac conditioning indicator for all HF patients.

Interestingly, Carpio et al. [91] evaluated the performance of obese patients with asthma and obese patients with misdiagnosed asthma (the presence of asthma-like symptoms) compared with obese control subjects during CPX. These authors observed that the level of dyspnea and the Borg- $\mathrm{VO}_{2}$ slope during $\mathrm{CPX}$ were higher in obese patients with asthma and in patients with misdiagnosed asthma than in obese control subjects. These authors concluded that the presence of asthma-like symptoms in obese individuals can be attributed to an increased perception of dyspnea, which, during exercise, is mainly associated with systemic inflammation and excessive ventilation for metabolic demands.

\section{Relationships between obesity, obesity hypoventilation syndrome, and obstructive sleep apnea}

Obesity is the most common known risk factor for the development of OSA [92]. The prevalence of OSA associated with high rates of morbidity and mortality increases with age; the peak incidence occurs at approximately age 55 , and the condition is more prevalent in males than in females by a ratio of 2:1 [93]. OSA is a systemic disease that causes an increase in TNF- $\alpha$, IL- 6 , insulin resistance, and glucose intolerance; these inflammatory cytokines have also been implicated in the immunological mechanisms of obesity [94]. Central obesity and increased neck circumference are predisposing factors for OSA [95, 96]. The resulting reduction or interruption of airflow, which occurs despite inspiratory effort, causes poor alveolar ventilation and oxyhemoglobin desaturation and, in cases of prolonged events, a progressive increase in the arterial partial pressure of carbon dioxide [97].

There is a strong association between OSA and metabolic syndrome as a whole or with its individual components [20]. The prevalence of metabolic syndrome in patients with OSA is $60 \%$, significantly higher than in general population [98]. This association is partially explained by the fact that patients with OSA are more likely to have high visceral adiposity as well as abnormal glucose metabolism [20, 99]. There is ample evidence suggesting that OSA may exacerbate or induce the majority of the components of metabolic syndrome. Some of these effects can be improved with the use of continuous positive airway pressure. However, the modest and inconsistent benefits obtained with this technique suggest that factors other than intermittent hypoxia or the apnea-hypopnea index may play an important role [20].

Some obese individuals develop obesity hypoventilation syndrome (OHS), which is defined by the triad of obesity, daytime hypoventilation, and sleep-disordered breathing and represents hypoventilation that occurs in the absence of a neuromuscular, mechanical, or metabolic cause [100]. The prevalence of OHS is estimated to be $8.5 \%$ in patients with OSA and $19-31 \%$ in obese subjects [101, 102]. OHS is more prevalent in women than in men, and postmenopausal women with OSA have a higher prevalence of OHS. This has been attributed to hormonal influences, particularly to the role of progesterone as a respiratory stimulant prior to menopause [103, 104]. Compared with eucapnic obese patients, patients with OHS have severe upper airway obstruction, restrictive pulmonary damage, decreased central respiratory drive, increased incidence of pulmonary hypertension, and increased mortality [100]. Among the possible mechanisms involved in the pathogenesis of OHS, some studies have reported damage to respiratory mechanics caused by obesity, leptin resistance leading to central hypoventilation, respiratory sleep disorders, and impaired compensatory responses to acute hypercapnia [97, 100, 102]. With respect to pulmonary function, patients with OHS present a reduction in chest wall compliance of approximately 2.5 -fold compared to patients with eucapnic obesity, as well as increased pulmonary resistance that is likely secondary to the reduction in FRC [100].

\section{Impact of treatment of obesity and weight loss on lung function}

As previously reported, obesity causes a number of changes in pulmonary function parameters. It is also known that 
weight loss improves these parameters, supporting the hypothesis that respiratory changes caused by obesity are a direct result of excess weight [45].

Several studies have shown that ERV, one of the parameters that is most significantly altered in obese individuals, increases after weight loss, adopting a calorie-restricted diet, or bariatric surgery [105, 106]. Hakala et al. [107] found a considerable increase in the ERV of patients whose BMI decreased from 45 to $39 \mathrm{~kg} / \mathrm{m}^{2}$ after adopting a calorie-restricted diet. Babb et al. showed that even modest reductions in weight, i.e., a decrease in BMI from 35 to $33 \mathrm{~kg} / \mathrm{m}^{2}$, induce an increase in end-expiratory lung volume during submaximal exercise [108]. Weight loss also causes changes in other parameters, including FRC, TLC, and gas exchange, resulting in increased blood oxygenation [107]. Respiratory muscle strength and dyspnea also improve after weight loss $[109,110]$.

In a recent publication, Mafort et al. [64] showed that obese and overweight patients exhibited a significant reduction in BMI after six months of intragastric balloon therapy; the median BMI value decreased from $39.1 \mathrm{~kg} / \mathrm{m}^{2}$ at the beginning of the evaluation to $34.5 \mathrm{~kg} / \mathrm{m}^{2}$ at the end of the evaluation $(p=0.0001)$. The reduction in BMI was accompanied by statistically significant reductions in TLC $(p=0.0001)$, FRC $(p=0.0001)$, residual volume $(p=0.0005)$, and ERV $(p=0.0001)$.

In obese patients with asthma, both surgical and nonsurgical weight loss are associated with improvement in symptoms, decreased use of medication, increased effectiveness of drug therapy, and a reduction in risk of exacerbation and hospital admission rate [111]. Improvements in lung function, including $\mathrm{FEV}_{1}, \mathrm{FVC}$, and Raw, after weight loss in obese patients with asthma have also been reported in several studies $[66,112-114]$. In a randomized study of obese adult patients with severe uncontrolled asthma, Dias-Júnior et al. [114] showed that following a weight loss program for a period of 6 months was associated with improvement in asthma control and lung function.

A decrease in BHR to methacholine after weight loss in obese individuals with asthma was reported by $\mathrm{Al}$ Alwan et al. [112] and by van Huisstede et al. [115]. In a prospective controlled study of obese individuals with asthma, Pakhale et al. [66] observed a significant improvement in BHR to methacholine compared to controls $(p=0.009)$ after 3 months of a behavioral weight loss program. Boulet et al. [67] evaluated severely obese patients with asthma before and after bariatric surgery and observed reduced BHR, increased lung volume, and noticeably decreased asthma symptoms and medication required to control asthma 12 months after surgery. This study also showed that reduction in BMI and improved BHR were correlated with a reduction in CRP.

\section{Conclusions}

Obesity causes mechanical compression of the diaphragm, lungs, and chest cavity, which can lead to restrictive pulmonary damage. Furthermore, excess fat decreases total respiratory system compliance, increases pulmonary resistance, and reduces respiratory muscle strength. It is interesting that metabolic syndrome also changes lung function and that the combination of obesity and metabolic syndrome seems to impair lung function even further. In obese and overweight patients, a strong correlation exists between lung function and body fat distribution, with greater impairment when fat accumulates in the chest and abdomen. Despite advances in the knowledge of pulmonary and systemic complications and of the biochemical abnormalities associated with obesity, longitudinal randomized studies are needed to assess the impact of weight loss on metabolic syndrome and lung function.

\section{Abbreviations}

BHR: bronchial hyperresponsiveness; BMl: body mass index;

CPX: cardiopulmonary exercise testing; CRP: C-reactive protein; DLco: carbon monoxide lung diffusion capacity; DXA: dual-energy X-ray absorptiometry;

EOA: early-onset allergic; ERV: expiratory reserve volume; FEV ${ }_{1}$ : forced expiratory volume in one second; FOT: forced oscillation technique; FRC: functional residual capacity; FVC: forced vital capacity; Hexim1: hexamethylene bis-acetamide inducible-1; HF: heart failure; IL-1: interleukin-1; IL-1 $\beta$ : interleukin-1- $\beta$; L-6: interleukin-6; LONA: late-onset non-allergic; MEP: maximal expiratory pressure; MIP: maximal inspiratory pressure; NO: nitric oxide; OHS: obesity hypoventilation syndrome;

OS: oxidative stress; OSA: obstructive sleep apnea; $\mathrm{P}(\mathrm{A}-\mathrm{a}) \mathrm{O}_{2}$ : alveolar-arterial oxygen gradient; PAI-I: type I plasminogen activation inhibitor; $\mathrm{PaO}_{2}$ : arterial partial pressure of oxygen; ROS: reactive oxygen species; SAH: systemic arterial hypertension; SOD: superoxide dismutase; T2DM: type 2 diabetes mellitus; TGF- $\beta$ : transforming growth factor- $\beta$; TLC: and total lung capacity; TNF-a: tumor necrosis factor- $a_{;} \mathrm{VCO}_{2}$ : carbon dioxide production; $\mathrm{V}_{\mathrm{E}}$ : minute ventilation; $\mathrm{VO}_{2}$ : oxygen consumption.

\section{Acknowledgements}

The authors wish to thank the Rio de Janeiro State Research Supporting Foundation (FAPERJ).

\section{Authors' contributions}

TTM had the idea to review the literature and drafted the manuscript; TTM and AJL found the papers; $\mathrm{CHC}$ and RR critically revised the manuscript and made substantial contributions. All authors read and approved the final manuscript.

\section{Competing interests}

The authors declare that they have no competing interests.

Received: 24 March 2016 Accepted: 10 May 2016

Published online: 12 July 2016

\section{References}

1. World Health Organization, WHO, Obesity: Preventing and Managing the Global Epidemic. Report of a WHO Consultation (WHO Technical Report Series 894) at http://www.who.int/nutrition/publications/obesity/WHO_TRS_ 894/en/. Accessed 10 Feb 2016.

2. Manna P, Jain SK. Obesity, oxidative stress, adipose tissue dysfunction, and the associated health risks: causes and therapeutic strategies. Metab Syndr Relat Disord. 2015;13:423-44.

3. Brazilian Association for the Study of Obesity and Metabolic Syndrome, ABESO, Brazilian Obesity Guidelines 2009/2010 at http://www.abeso.org.br/pdf/ diretrizes_brasileiras_obesidade_2009_2010_1.pdf. Accessed 22 Jan 2016. 
4. de Oliveira ML, Santos LM, da Silva EN. Direct healthcare cost of obesity in Brazil: an application of the cost-of-illness method from the perspective of the public health system in 2011. PLoS One. 2015;10:e0121160.

5. Marseglia L, Manti S, D’Angelo G, Nicotera A, Parisi E, Di Rosa G, et al. Oxidative stress in obesity: a critical component in human diseases. Int J Mol Sci. 2014;16:378-400

6. Hodgson LE, Murphy PB, Hart N. Respiratory management of the obese patient undergoing surgery. J Thorac Dis. 2015;7:943-52.

7. Calle EE, Thun MJ, Petrelli JM, Rodriguez C, Heath Jr CW. Body-mass index and mortality in a prospective cohort of U.S. adults. N Engl J Med. 1999;341:1097-105.

8. Redinger RN. The pathophysiology of obesity and its clinical manifestations. Gastroenterol Hepatol. 2007;3:856-63.

9. Masmiquel L, Leiter LA, Vidal J, Bain S, Petrie J, Franek E, et al. LEADER 5: prevalence and cardiometabolic impact of obesity in cardiovascular high-risk patients with type 2 diabetes mellitus: baseline global data from the LEADER trial. Cardiovasc Diabetol. 2016;15:29.

10. Benotti P, Wood GC, Argyropoulos G, Pack A, Keenan BT, Gao X, et al. The impact of obstructive sleep apnea on nonalcoholic fatty liver disease in patients with severe obesity. Obesity (Silver Spring). 2016;24:871-7.

11. Kairaitis K, Foster S, Amatoury J, Verma M, Wheatley JR, Amis TC. Pharyngeal mucosal wall folds in subjects with obstructive sleep apnea. J Appl Physiol. 2015;118(6):707-15.

12. Badran M, Yassin BA, Fox N, Laher I, Ayas N. Epidemiology of sleep disturbances and cardiovascular consequences. Can J Cardiol. 2015;31:873-9.

13. Guerra S, Wright AL, Morgan WJ, Sherrill DL, Holberg CJ, Martinez FD. Persistence of asthma symptoms during adolescence: role of obesity and age at the onset of puberty. Am J Respir Crit Care Med. 2004;170:78-85.

14. Lu Y, Van Bever HP, Lim TK, Kuan WS, Goh DY, Mahadevan M, et al. Obesity, asthma prevalence and IL-4: Roles of inflammatory cytokines, adiponectin and neuropeptide Y. Pediatr Allergy Immunol. 2015;26:530-6.

15. Ulrik CS. Asthma symptoms in obese adults: the challenge of achieving asthma control. Expert Rev Clin Pharmacol. 2016;9(1):5-8.

16. Cortés-Télles A, Torre-Bouscoulet L, Silva-Cerón M, Mejía-Alfaro R, Syed N, Zavorsky GS, et al. Combined effects of mild-to-moderate obesity and asthma on physiological and sensory responses to exercise. Respir Med. 2015;109:1397-403.

17. Vozoris NT1, O'Donnell DE. Prevalence, risk factors, activity limitation and health care utilization of an obese, population-based sample with chronic obstructive pulmonary disease. Can Respir J. 2012;19(3):e18-24.

18. Hanson C, Rutten EP, Wouters EF, Rennard S. Influence of diet and obesity on COPD development and outcomes. Int J Chron Obstruct Pulmon Dis. 2014;9:723-33.

19. Beltrán-Sánchez H, Harhay MO, Harhay MM, McElligott S. Prevalence and trends of metabolic syndrome in the adult U.S. population, 1999-2010. J Am Coll Cardiol. 2013;62:697-703.

20. Baffi CW, Wood L, Winnica D, Strollo PJ, Gladwin MT, Que LG, et al. Metabolic syndrome and the lung. Chest. 2016. [Epub ahead of print].

21. Samson SL, Garber AJ. Metabolic syndrome. Endocrinol Metab Clin North Am. 2014;43:1-23.

22. Lee H, Kim SR, Oh Y, Cho SH, Schleimer RP, Lee YC. Targeting insulin-like growth factor-l and insulin-like growth factor-binding protein-3 signaling pathways. A novel therapeutic approach for asthma. Am J Respir Cell Mol Biol. 2014:50:667-77.

23. Segula D. Complications of obesity in adults: a short review of the literature. Malawi Med J. 2014;26:20-4.

24. Fernández-Sánchez A, Madrigal-Santillán E, Bautista M, Esquivel-Soto J, Morales-González A, Esquivel-Chirino C, et al. Inflammation, oxidative stress, and obesity. Int J Mol Sci. 2011;12:3117-32.

25. Fonseca-Alaniz MH, Takada J, Alonso-Vale MI, Lima FB. Adipose tissue as an endocrine: organ: from theory to practice. J Pediatr. 2007;83 Suppl 5:192-203.

26. Möller K, Ostermann Al, Rund K, Thoms S, Blume C, Stahl F, et al. Influence of weight reduction on blood levels of $\mathrm{C}$-reactive protein, tumor necrosis factor-a, interleukin-6, and oxylipins in obese subjects. Prostaglandins Leukot Essent Fatty Acids. 2016;106:39-49.

27. Stienstra R, Tack CJ, Kanneganti TD, Joosten LA, Netea MG. The inflammasome puts obesity in the danger zone. Cell Metabol. 2012;15:10-8.

28. Naugler WE, Karin M. The wolf in sheep's clothing: the role of interleukin-6 in immunity, inflammation and cancer. Trends Mol Med. 2008;14:109-19.

29. Pedersen JM, Budtz-Jørgensen E, Mortensen EL, Bruunsgaard H, Osler M, Sørensen TI, et al. Late midlife C-reactive protein and interleukin-6 in middle aged danish men in relation to body size history within and across generations. Obesity. 2016;24:461-8.
30. Stenlöf K, Wernstedt I, Fjällman T, Wallenius V, Wallenius K, Jansson JO Interleukin-6 levels in the central nervous system are negatively correlated with fat mass in overweight/obese subjects. J Clin Endocrinol Metab. 2003;88:4379-83.

31. Drougard A, Fournel A, Valet $P$, Knauf C. Impact of hypothalamic reactive oxygen species in the regulation of energy metabolism and food intake. Front Neurosci. 2015;9:56.

32. Amirkhizi F, Siassi F, Minaie S, Djalali M, Rahimi A, Chamari M. Is obesity associated with increased plasma lipid peroxidation and oxidative stress in women. ARYA Atheroscler. 2007;2:189-92.

33. Ozata M, Mergen M, Oktenli C, Aydin A, Sanisoglu SY, Bolu E, et al. Increased oxidative stress and hypozincemia in male obesity. Clin Biochem. 2002;35:627-31.

34. Goossens $\mathrm{GH}$. The role of adipose tissue dysfunction in the pathogenesis of obesity-related insulin resistance. Physiol Behav. 2008;94:206-18.

35. Dhar-Mascareno M, Ramirez SN, Rozenberg I, Rouille Y, Kral JG, Mascareno EJ. Hexim1, a novel regulator of leptin function, modulates obesity and glucose disposal. Mol Endocrinol. 2016;30:314-24.

36. Hukshorn CJ, Lindeman JH, Toet KH, Saris WH, Eilers PH, WesterterpPlantenga MS, et al. Leptin and the proinflammatory state associated with human obesity. J Clin Endocrinol Metab. 2004;89:1773-8.

37. Deng $Y$, Scherer PE. Adipokines as novel biomarkers and regulators of the metabolic syndrome. Ann N Y Acad Sci. 2010;1212:E1-19.

38. Ouedraogo R, Gong Y, Berzins B, Wu X, Mahadev K, Hough K, et al. Adiponectin deficiency increases leukocyte-endothelium interactions via upregulation of endothelial cell adhesion molecules in vivo. J Clin Invest. 2007;117:1718-26.

39. Fujita K, Nishizawa H, Funahashi T, Shimomura I, Shimabukuro M. Systemic oxidative stress is associated with visceral fat accumulation and the metabolic syndrome. Circ J. 2006;70:1437-42.

40. Chen Y, Pitzer AL, Li X, Li PL, Wang L, Zhang Y. Instigation of endothelial Nlrp3 inflammasome by adipokine visfatin promotes inter-endothelial junction disruption: role of HMGB1. J Cell Mol Med. 2015;19:2715-27.

41. Moschen AR, Kaser A, Enrich B, Mosheimer B, Theurl M, Niederegger $\mathrm{H}$, et al. Visfatin, an adipocytokine with proinflammatory and immunomodulating properties. J Immunol. 2007;178:1748-58.

42. Kawanami D, Maemura K, Takeda N, Harada T, Nojiri T, Imai Y, et al. Direct reciprocal effects of resistin and adiponectin on vascular endothelial cells: a new insight into adipocytokine-endothelial cell interactions. Biochem Biophys Res Commun. 2004;314:415-9.

43. Pihl E, Zilmer K, Kullisaar T, Kairane C, Mägi A, Zilmer M. Atherogenic inflammatory and oxidative stress markers in relation to overweight values in male former athletes. Int J Obes. 2006;30:141-6.

44. Okla M, Kang I, da Kim M, Gourineni V, Shay N, Gu L, et al. Ellagic acid modulates lipid accumulation in primary human adipocytes and human hepatoma Huh7 cells via discrete mechanisms. J Nutr Biochem. 2015:26:82-90.

45. Brazzale DJ, Pretto JJ, Schachter LM. Optimizing respiratory function assessments to elucidate the impact of obesity on respiratory health. Respirology. 2015;20:715-21.

46. Steier J, Lunt A, Hart N, Polkey MI, Moxham J. Observational study of the effect of obesity on lung volumes. Thorax. 2014;69:752-9.

47. Koo P, Gartman EJ, Sethi JM, McCool FD. Physiology in Medicine: physiological basis of diaphragmatic dysfunction with abdominal herniasimplications for therapy. Appl Physiol. 2015:118:142-7.

48. Unterborn J. Pulmonary function testing in obesity, pregnancy, and extremes of body habitus. Clin Chest Med. 2001:22:759-67.

49. Salome CM, King GG, Berend N. Physiology of obesity and effects on lung function. J Appl Physiol. 2010;108:206-11.

50. de Lucas RP, Rodríguez González-Moro JM, Rubio SY. Obesity and lung function. Arch Bronconeumol. 2004:40 Suppl 5:27-31.

51. Rasslan Z, Stirbulov R, Lima CA, Saad JR. Lung function and obesity. Rev Bras Clínica Médica. 2009;7:36-9.

52. Jones RL, Nzekwu MM. The effects of body mass index on lung volumes. Chest. 2006;130:827-33.

53. Mafort TT, Madeira E, Madeira M, Guedes EP, Moreira RO, de Mendonça LM, et al. Intragastric balloon for the treatment of obesity: evaluation of pulmonary function over a 3-month period. Lung. 2012;190:671-6.

54. Melo LC, Silva MA, Calles ACN. Obesity and lung function: a systematic review. Einstein. 2014;12:120-5.

55. Carpio C, Santiago A, de García Lorenzo A, Alvarez-Sala R. Changes in lung function testing associated with obesity. Nutr Hosp. 2014;30:1054-62.

56. Thyagarajan B, Jacobs Jr DR, Apostol GG, Smith L, Jensen RL, Crapo RO, et al. Longitudinal association of body mass index with lung function: the CARDIA study. Respir Res. 2008;9:31. 
57. Pellegrino R, Gobbi A, Antonelli A, Torchio R, Gulotta C, Pellegrino GM, et al. Ventilation heterogeneity in obesity. J Appl Physiol. 2014;116:1175-81.

58. Mahadev S, Salome CM, Berend N, King GG. The effect of low lung volume on airway function in obesity. Respir Physiol Neurobiol. 2013;188:192-9.

59. Manuel AR, Hart N, Stradling JR. Correlates of obesity-related chronic ventilatory failure. BMJ Open Respir Res. 2016;3(1):e000110.

60. Chlif M, Keochkerian D, Choquet D, Vaidie A, Ahmaidi S. Effects of obesity on breathing pattern, ventilatory neural drive and mechanics. Respir Physiol Neurobiol. 2009;168:198-202

61. Arena R, Cahalin LP. Evaluation of cardiorespiratory fitness and respiratory muscle function in the obese population. Prog Cardiovasc Dis. 2014;56:457-64.

62. Rivas E, Arismendi E, Agustí A, Sanchez M, Delgado S, Gistau C, et al. Ventilation/perfusion distribution abnormalities in morbidly obese subjects before and after bariatric surgery. Chest. 2015;147:1127-34.

63. Saydain G, Beck KC, Decker PA, Cowl CT, Scanlon PD. Clinical significance of elevated diffusion capacity. Chest. 2004;125:446-52.

64. Mafort TT, Madeira E, Madeira M, Guedes EP, Moreira RO, de Mendonça LM, et al. Six-month intragastric balloon treatment for obesity improves lung function, body composition, and metabolic syndrome. Obes Surg. 2014;24:232-40.

65. Dixon AE, Subramanian M, DeSarno M, Black K, Lane L, Holguin F. A pilot randomized controlled trial of pioglitazone for the treatment of poorly controlled asthma in obesity. Respir Res. 2015;16:143.

66. Pakhale S, Baron J, Dent R, Vandemheen K, Aaron SD. Effects of weight loss on airway responsiveness in obese adults with asthma: does weight loss lead to reversibility of asthma? Chest. 2015;147:1582-90.

67. Boulet LP, Turcotte H, Martin J, Poirier P. Effect of bariatric surgery on airway response and lung function in obese subjects with asthma. Respir Med. 2012;106:651-60.

68. Torchio R, Gobbi A, Gulotta C, Dellacà R, Tinivella M, Hyatt RE, et al. Mechanical effects of obesity on airway responsiveness in otherwise healthy humans. J Appl Physiol. 2009;107:408-16.

69. Brumpton BM, Leivseth L, Romundstad PR, Langhammer A, Chen Y, Camargo Jr CA, et al. The joint association of anxiety, depression and obesity with incident asthma in adults: the HUNT study. Int J Epidemiol. 2013;42:1455-63.

70. Hjellvik V, Tverdal A, Furu K. Body mass index as predictor for asthma: a cohort study of 118,723 males and females. Eur Respir J. 2010;35:1235-42.

71. Groth SW, Rhee H, Kitzman H. Relationships among obesity, physical activity and sedentary behavior in young adolescents with and without lifetime asthma. J Asthma. 2016;53:19-24.

72. Yawn BP, Rank MA, Bertram SL, Wollan PC. Obesity, low levels of physical activity and smoking present opportunities for primary care asthma interventions: an analysis of baseline data from The Asthma Tools Study. NPJ Prim Care Respir Med. 2015;25:15058.

73. Schatz M, Zeiger RS, Yang SJ, Chen W, Sajjan S, Allen-Ramey F, et al. Prospective study on the relationship of obesity to asthma impairment and risk. J Allergy Clin Immunol Pract. 2015;3:560-5.

74. de Lima Azambuja R, da Costa Santos Azambuja LS, Costa C, Rufino R. Adiponectin in asthma and obesity: protective agent or risk factor for more severe disease? Lung. 2015;193:749-55.

75. Ballantyne D, Scott H, MacDonald-Wicks L, Gibson PG, Wood L. Resistin is a predictor of asthma risk and resistin: adiponectin ratio is a negative predictor of lung function in asthma. Clin Exp Allergy. 2016. [Epub ahead of print].

76. Heinzmann-Filho JP, Vendrusculo FM, Woszezenki CT, Piva TC, Santos AN, Barcellos $A B$, et al. Inspiratory muscle function in asthmatic and healthy subjects: influence of age, nutrition and physical activity. J Asthma. 2016. [Epub ahead of print].

77. Charron $\mathrm{CB}$, Pakhalé S. The role of airway hyperresponsiveness measured by methacholine challenge test in defining asthma severity in asthma-obesity syndrome. Curr Opin Allergy Clin Immunol. 2016. [Epub ahead of print].

78. Bates $\mathrm{JH}$. Physiological mechanisms of airways hyperresponsiveness in obese asthma. Am J Respir Cell Mol Biol. 2016. [Epub ahead of print].

79. Cheung AS, de Rooy C, Hoermann R, Gianatti EJ, Hamilton EJ, Roff G, et al. Correlation of visceral adipose tissue measured by Lunar Prodigy dual x-ray absorptiometry with MRI and CT in older men. Int J Obes. 2016. [Epub ahead of print].

80. Rondanelli M, Klersy C, Perna S, Faliva MA, Montorfano G, Roderi P, et al. Effects of two-months balanced diet in metabolically healthy obesity: lipid correlations with gender and BMI-related differences. Lipids Health Dis. 2015;14:139.

81. Tarnoki AD, Tarnoki DL, Medda E, Cotichini R, Stazi MA, Fagnani C, et al. Bioimpedance analysis of body composition in an international twin cohort. Obes Res Clin Pract. 2014;8:e201-98.
82. Mulasi U, Kuchnia AJ, Cole AJ, Earthman CP. Bioimpedance at the bedside: current applications, limitations, and opportunities. Nutr Clin Pract. 2015;30:180-93.

83. Wang $\mathrm{H}$, Chen $\mathrm{YE}$, Eitzman DT. Imaging body fat: techniques and cardiometabolic implications. Arterioscler Thromb Vasc Biol. 2014;34:2217-23.

84. Steele RM, Finucane FM, Griffin SJ, Wareham NJ, Ekelund U. Obesity is associated with altered lung function independently of physical activity and fitness. Obesity. 2009;17:578-84.

85. Enzi G, Gasparo M, Biondetti PR, Fiore D, Semisa M, Zurlo F. Subcutaneous and visceral fat distribution according to sex, age, and overweight, evaluated by computer tomography. Am J Clin Nutr. 1986;44:739-46.

86. Bernhardt V, Wood HE, Moran RB, Babb TG. Dyspnea on exertion in obese men. Respir Physiol Neurobiol. 2013;185:241-8.

87. Bernhardt V, Stickford JL, Bhammar DM, Babb TG. Aerobic exercise training without weight loss reduces dyspnea on exertion in obese women. Respir Physiol Neurobiol. 2016;221:64-70.

88. Salvadego D, Sartorio A, Agosti F, Tringali G, Patrizi A, Mauro AL, et al. Acute respiratory muscle unloading by normoxic helium- $\mathrm{O}_{2}$ breathing reduces the $\mathrm{O}_{2}$ cost of cycling and perceived exertion in obese adolescents. Eur J Appl Physiol. 2015;115:99-109.

89. Gibson N, Johnston K, Bear N, Stick S, Logie K, Hall GL. Expiratory flow limitation and breathing strategies in overweight adolescents during submaximal exercise. Int J Obes. 2014;38:22-6.

90. Hothi SS, Tan DK, Partridge G, Tan LB. Is low VO2max/kg in obese heart failure patients indicative of cardiac dysfunction? Int J Cardiol. 2015;184:755-62.

91. Carpio C, Villasante C, Galera R, Romero D, de Cos A, Hernanz A, et al. Systemic inflammation and higher perception of dyspnea mimicking asthma in obese subjects. J Allergy Clin Immunol. 2016;137:718-26.

92. Duarte RL, Magalhães-da-Silveira FJ. Factors predictive of obstructive sleep apnea in patients undergoing pre-operative evaluation for bariatric surgery and referred to a sleep laboratory for polysomnography. J Bras Pneumol. 2015:41:440-8.

93. Pinto JA, Ribeiro DK, Cavallini AF, Duarte C, Freitas GS. Comorbidities associated with obstructive sleep apnea: a retrospective study. Int Arch Otorhinolaryngol. 2016;20:145-50.

94. Aurora RN, Punjabi NM. Obstructive sleep apnoea and type 2 diabetes mellitus: a bidirectional association. Lancet Respir Med. 2013;1:329-38.

95. Peromaa-Haavisto $\mathrm{P}$, Tuomilehto $H$, Kössi J, Virtanen J, Luostarinen M, Pihlajamäki J, et al. Prevalence of obstructive sleep apnoea among patients admitted for bariatric surgery: a prospective multicentre trial. Obes Surg. 2015. [Epub ahead of print].

96. Ren SL, Li YR, Jen R, Wu JX1, Ye JY. Effects of altered intra-abdominal pressure on the upper airway collapsibility in a porcine model. Chin Med J. 2015;128:3204-10.

97. Pierce AM, Brown LK. Obesity hypoventilation syndrome: current theories of pathogenesis. Curr Opin Pulm Med. 2015;21:557-62.

98. Gil JS, Drager LF, Guerra-Riccio GM, Mostarda C, Irigoyen MC, Costa-Hong V, et al. The impact of metabolic syndrome on metabolic, pro-inflammatory and prothrombotic markers according to the presence of high blood pressure criterion. Clinics (Sao Paulo). 2013;68:1495-501.

99. Bozkurt NC, Beysel S, Karbek B, Unsal IO, Cakir E, Delibasi T. Visceral obesity mediates the association between metabolic syndrome and obstructive sleep apnea syndrome. Metab Syndr Relat Disord. 2016;14:217-21.

100. Chau EH, Lam D, Wong J, Mokhlesi B, Chung F. Obesity hypoventilation syndrome: a review of epidemiology, pathophysiology, and perioperative considerations. Anesthesiology. 2012;117:188-205.

101. BaHammam AS. Prevalence, clinical characteristics, and predictors of obesity hypoventilation syndrome in a large sample of Saudi patients with obstructive sleep apnea. Saudi Med J. 2015;36:181-9.

102. Shetty S, Parthasarathy S. Obesity hypoventilation syndrome. Curr Pulmonol Rep. 2015;4:42-55.

103. BaHammam AS, Pandi-Perumal SR, Piper A, Bahammam SA, Almeneessier AS, Olaish AH, et al. Gender differences in patients with obesity hypoventilation syndrome. J Sleep Res. 2016. [Epub ahead of print].

104. Jehan S, Masters-Isarilov A, Salifu I, Zizi F, Jean-Louis G, Pandi-Perumal SR, et al. Sleep disorders in postmenopausal women. J Sleep Disord Ther. 2015;4:1000212.

105. Thomas PS, Cowen ER, Hulands G, Milledge JS. Respiratory function in the morbidly obese before and after weight loss. Thorax. 1989;44:382-6.

106. Littleton SW. Impact of obesity on respiratory function. Respirology. 2012:17:43-9.

107. Hakala K, Mustajoki P, Aittomäki J, Sovijärvi AR. Effect of weight loss and body position on pulmonary function and gas exchange abnormalities in morbid obesity. Int J Obes Relat Metab Disord. 1995;19:343-6. 
108. Babb TG, Wyrick BL, Chase PJ, Delorey DS, Rodder SG, Feng MY, et al. Weight loss via diet and exercise improves exercise breathing mechanics in obese men. Chest. 2011;140:454-60.

109. Weiner P, Waizman J, Weiner M, Rabner M, Magadle R, Zamir D. Influence of excessive weight loss after gastroplasty for morbid obesity on respiratory muscle performance. Thorax. 1998:53:39-42.

110. Bernhardt V, Babb TG. Weight loss reduces dyspnea on exertion in obese women. Respir Physiol Neurobiol. 2014;204:86-92.

111. Ulrik CS. Asthma and obesity: is weight reduction the key to achieve asthma control? Curr Opin Pulm Med. 2016;22:69-73.

112. Al-Alwan A, Bates JH, Chapman DG, Kaminsky DA, DeSarno MJ, Irvin CG, et al. The nonallergic asthma of obesity. A matter of distal lung compliance. Am J Respir Crit Care Med. 2014;189:1494-502.

113. Hewitt S, Humerfelt S, Søvik T, Aasheim ET, Risstad H, Kristinsson J, et al. Long-term improvements in pulmonary function 5 years after bariatric surgery. Obes Surg. 2014;24:705-11.

114. Dias-Júnior SA, Reis M, de Carvalho-Pinto RM, Stelmach R, Halpern A, Cukier A. Effects of weight loss on asthma control in obese patients with severe asthma. Eur Respir J. 2014;43:1368-77.

115. van Huisstede A, Rudolphus A, Castro Cabezas M, Biter LU, van de Geijn GJ, Taube C, Hiemstra PS, et al. Effect of bariatric surgery on asthma control, lung function and bronchial and systemic inflammation in morbidly obese subjects with asthma. Thorax. 2015;70:659-67.

\section{Submit your next manuscript to BioMed Central} and we will help you at every step:

- We accept pre-submission inquiries

- Our selector tool helps you to find the most relevant journal

- We provide round the clock customer support

- Convenient online submission

- Thorough peer review

- Inclusion in PubMed and all major indexing services

- Maximum visibility for your research

Submit your manuscript at www.biomedcentral.com/submit 